ISSN: 2638-4809

Volume 2, Issue 1, 2019, PP: 11-17

\title{
Severe Early Childhood Caries - A Clinical Case Report
}

\section{Dobrinka M. Damyanova*}

*Chief. Assistant Professor, Post-doctoral, Medical University-Varna, Prof. Dr. Paraskev Stoyanov, Bulgaria. Professor, Faculty of Dental Medicine, Department of Pediatric Dental Medicine, Bulgaria. dr_damyanova@abv.bg

*Corresponding author: Dr. Dobrinka Damyanova Phd, Department of Pediatric Dentistry, Faculty of Dental Medicine, Medical University-Varna, Bulgaria.

\section{Abstract}

Introduction: The most common cause of general anesthesia for children up to 5 years of age in Bulgaria is caries of early childhood, followed by non-cooperative children due to the strong anxiety of dental treatment. Dental caries in the primary dentition of children aged 5 years and from 1 to 3 years are still one of the major health problems in the United States. The aim is to examine the severity of early childhood caries, their complications and the need for restoration.

Case Presentation: On the dental chair is sitting a 3 years and 7 months old girl. Dental status showed that the teeth 51, 52, 61, 62 were diagnosed Fracture coronae dentis. Teeth 54, 64 were diagnosed Periodontitis chronica granulomatosa diffusa cum fistulae. Cavity (d3) and irreversible lesions are the teeth 53, 63, 81, 82. Deep and cavity caries of the occlusal fissure have teeth 65, 75, 84, 85.Teeth 55, 72, 74 have a diagnosis of symptomatic and open pulpitis (d4). The treatment was conducted on general and local anesthesia in the clinic of the University in Varna. Operators: Doctors, specialists in pediatric dentistry.

Discussion: The patient have pain on palpation and percussion. The Silness and Loe plaque index is 2.33, which indicates poor oral hygiene. Diagnosis: Severe Early Childhood Caries. The child not systemic medical condition. The definition of severe early childhood caries (S-ECC) is any sign of smooth-surface caries in a child younger than three years of age, and from ages three through five, one or more cavitated, missing, or filled smooth surfaces in primary maxillary anterior teeth or a decayed, missing, or filled score of greater than or equal to four (age 3), greater than or equal to five (age 4), or greater than or equal to six (age 5). In this case primary teeth need a restoration, and in heavier cases and extraction.

Conclusion: 1. Children who have suffered from ECC should be treated by minimally invasive cavity preparation with preventive fillings for primary teeth. 2. The restorations for teeth are made of modern adhesives such as glass-ionomer cements and compomers.

Keywords: ECC, general anesthesia, cavitated caries lesions

\section{INTRODUCTION}

The AAPD recognizes early childhood caries as a significant chronic disease resulting from an imbalance of multiple risk and protective factors over time. Hallett KB and co-authors, 2006, with a survey of 2,515 children aged 4-5 and the DMFT /dmfs, applied a questionnaire to obtain social, demographic information about birth, infant feeding, oral and general health. Scientists have found that artificiallyfed 4-5 year old Australian children have a severe ECC grade [1]. Dental caries in the primary dentition of children aged 5 years and from 1 to 3 years are still one of the major health problems in the United States. [2].

According to Andreeva R. 2018, the most common cause of treatment under general anesthesia for children up to 5 years in Varna, Bulgaria is the early childhood caries, followed by non-cooperative children and due to the strong anxiety of dental treatment [3, 4].

The statistical model for caries for pre-school children in the northern Brisbane region was built by Hallett 
KB and co-authors in 2003, using certain social and behavioral determinants. Epidemiological data can also be used to improve public planning of oral health services and resource allocation in the region [5].

The definition of severe early childhood caries (S-ECC) is any sign of smooth-surface caries in a child younger than three years of age, and from ages three through five, one or more cavitated, missing (due to caries), or filled smooth surfaces in primary maxillary anterior teeth or a decayed, missing, or filled score of greater than or equal to four (age 3), greater than or equal to five (age 4), or greater than or equal to six (age 5) [6]. Microbial risk markers for ECC include MS and Lactobacillus species [8].

Aim: The aim is to examine the severity of early childhood caries, their complications and the need for restoration.

\section{Case Presentation}

Anamnesis: On the dental chair is sitting a 3 years and 7 months old girl. The anamnesis is taken by the patient mother. Passport part: Name: M. S.; Age 3 years and 7 months; Sex: female; Address: Dobrich, Bulgaria. Purpose of visit: She came for a prophylactic examination. It is the first examination with her.

Common Medical History: The patient does not have any common diseases. She does not have a known allergy. She is not taking any medication. She does not had any hospitalizations. The child is not taking any medication. There have not been any complications during pregnancy or labor. The child is strongly negative towards the dental treatment. The patient also went through a detailed anesthesiological consultation. Methods of influence of children's behavior: maintenance of positive behavior by means of arrangement of dental treatment and film-model.

History of Oral Diseases: She does not have any unfavorable dental visits. The patient does not have any bad oral habits and there is no known history of oral bad habits. She does not have an orthodontic treatment in this moment and not in the past. She did not had any facial or dental traumas.

Oral Hygiene: The mother reports that brushes teeth her child once a day with you, before going to bed. Most of the time the mother is present while brushing. Toothpaste: She used to have several toothpastes from different brands - Nenedent, Elmex.
At the moment she uses gum toothpaste containing 500 ppm fluoride. Fluoride intake: The described that: 1. Till know her child did not take fluoride in any form following the advice of her pediatrician. 2. She use to buy baby water without fluoride.

Nutrition Habits: The patient consumes juice and frequent in-between meal consumption of sugaradded snacks or drinks every day increase the risk of caries. Mother,s theoretical knowledge for dental health is insufficient.

Status: General status. The physical development is according to her age. The psychological development is according to her age.

Status Localis Extraoralis: No asymmetries and no swelling are inspected. No pathologies on the lips and the face in general. The head and neck muscles were palpated and presented without pathology. Lymph nodes were palpated and presented without any pathological pain or swelling bilaterally. Both TMJs were palpated and presented without any pathology. The opening amplitude of the mandible was assessed and showed without any reduction.

Status Localis Intraoralis: The gingival presents with a reddish color and the texture is stippled. This is normal because of the increased vascularity and the thinner epithelium in children. The tongue is without pathology. Her upper and lower labial frenulum have mucosal attachment. Plaque presented mainly on the buccal and lingual surfaces.

Dental Status: Dental status showed that the teeth 51, 52, 61, 62 were diagnosed Fracture coronae dentis. Teeth 54, 64 were diagnosed Periodontitis chronica granulomatosa diffusa cum fistulae. Cavity (d3) and irreversible lesions are the teeth 53, 63, 81, 82. Deep and cavity caries of the occlusal fissure have teeth $65,75,84,85$.Teeth $55,72,74$ have a diagnosis of symptomatic and open pulpitis (d4).

Diagnostic Scale-Code: d3 - irreversible cavity caries lesions in the dentin; $\mathrm{d} 4$ - dentinal lesion with pulp involvement; Irreversible complicated caries lesions of pulpitis.

The patients have pain on palpation and percussion, Figure 1. 


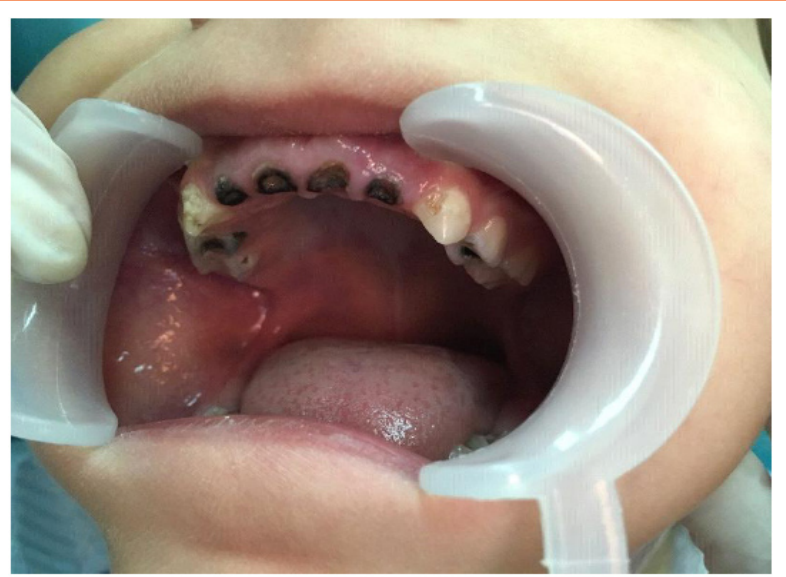

Fig 1. Status localis intraoralis. A child, a girl of 3 years and 7 months. Diagnosis Severe Early Childhood Caries Indices: $\mathrm{dmf}$ index. The $\mathrm{dmf}$ index is applied to the permanent dentition and is expressed as the total number of teeth or surfaces that are decayed (d), missing (m), or filled (f) in an individual. Scores per individual can range from 0 to 28 . The third molars are not counted. The teeth not counted are unerupted teeth, congenitally missing teeth or supernumerary teeth, teeth removed for reasons other than dental caries, and primary teeth retained in the permanent dentition. The dmf is 17 (decayed teeth).

Diagnosis: Severe Early Childhood Caries - (S-ECC)

Silness-Löe Index - (Silness and Löe, 1964), [7].

The measurement of the state of oral hygiene by Silness - Loe plaque index is based on recording both soft debris and mineralized deposits on the following teeth: 55, 62, 64, 75, 82 and 85 . The representative teeth are evaluated according to the following scale: 0 - no plaque, 1- small amount of plaque, 2 - moderate amount of plaque, 3 - great amount of plaque. The average of all six teeth is calculated. The Silness and Loe plaque index is 2.33 , which indicates poor oral hygiene.

Caries Risk Assessment: Biological factors. Parent with active carious lesions. Protective factors: Brushing with fluoride toothpaste. Clinical information: Child with more than $1 \mathrm{dmf}$, with active lesions, with plaque on teeth. Conclusion: Child M. S. belong into the high risk group.

Treatment Plan: Treatment of hard teeth structures, pulp and periodontium. The treatment was conducted on general and local anesthesia of the child in the clinic of the University Medical Dental Center at the Faculty of Dental Medicine, Medical University „, Prof. d-r Paraskev Stoyanov" in Varna, Bulgaria. Operators: Doctors, specialists in pediatric dentistry.

- Teeth 54, 64 - further diagnosis: periapical X- ray and treatment plan is extraction

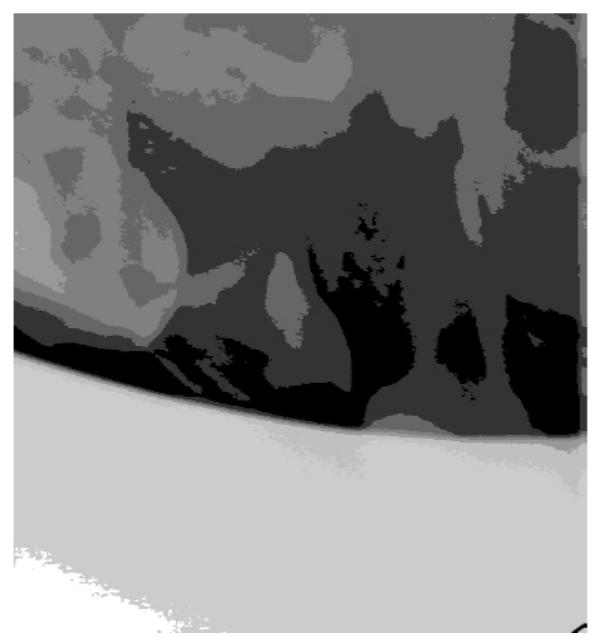

Fig 2. X-ray examination of the periapical lesion of the tooth 54 for diagnosis and determination of the therapeutic or surgical treatment plan 
Severe Early Childhood Caries - A Clinical Case Report

Teeth $51,52,61,62$ - treatment plan is extraction.

Teeth 53, 63, 81, 82 - treatment plan is caries removal, filled tooth surfaces with resin-modified glassionomer cement (Riva Light Cure Glass Ionomer Cement, SDI).

Teeth 65, 75, 84, 85 - treatment plan is caries removal, filled tooth surfaces with compomer Dyract ${ }^{\mathrm{R}} \mathrm{XP}$, DENTSPLY DeTrey GmbH Germany

Teeth 55, 72, 74 - treatment with Pulpotomy, filled tooth surfaces with compomer Dyract ${ }^{\mathrm{R}} \mathrm{XP}$, DENTSPLY DeTrey GmbH Germany, Figure 3.

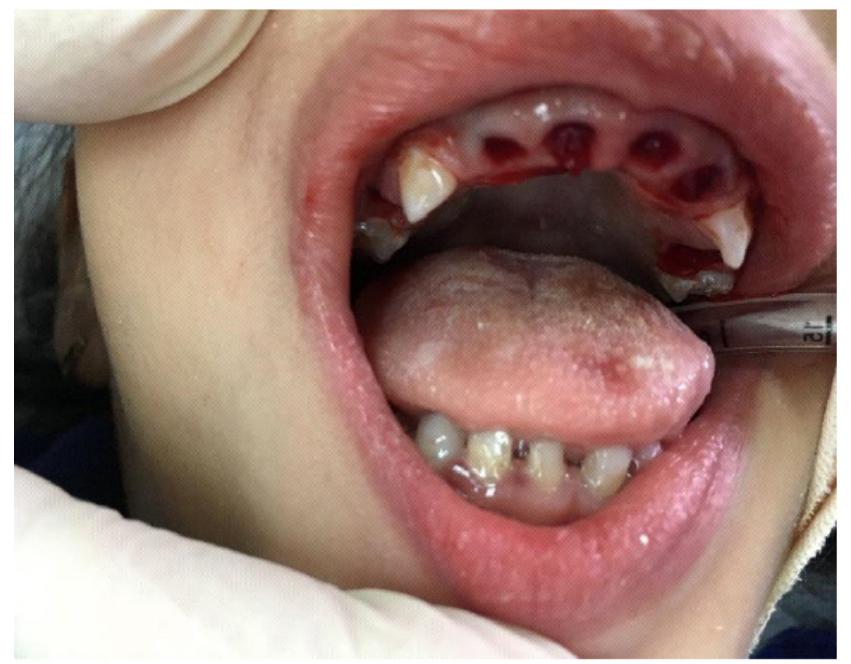

Fig.3. After treatment of hard teeth structures, pulp and periodontium in general and local anesthesia. With the diagnosis we extracted the teeth 54, 52, 51, 61, 62, 64.

We have prescribed polyvitamins and child's syrup for analgesia Nurofen (Massmould Ltd, Unit 21 Cosgrove Way, Luton, Bedfordshire, Great Britain).

\section{Individual Prophylaxis Program, ORAL HYGIENE}

Instruct the mother in proper oral hygiene. Toothbrushing should be performed for children by a parent twice daily, using a soft toothbrush of ageappropriate size. In children ages three to six, a peasized amount of fluoridated toothpaste should be used 2 per day for 3-5 min. Professional oral hygiene should be performed every 3 months as the child is in high risk group for caries development.

Fluoride Prophylaxis: Daily fluoride prophylaxis should not exceed $0,250 \mathrm{mg}$ for 3 year old child. Topical fluoride prophylaxis with toothpaste using pea size amount of paste containing 500 ppm. Endogenous prophylaxis with fluoride tablets $(0,250 \mathrm{ppm})$ or fluoride containing water not exceeding $0,250 \mathrm{ml} / \mathrm{l}$.

Professional fluoride prophylaxis. For high risk patients, 4 fluoride applications are recommended yearly at each quarterly dental visit. Professional fluoride varnishes are indicated, because she has high risk of caries development. They are applied in an interval of 3 months.
Alimentary Regime: Frequent consumption of between-meal snacks and beverages containing sugars increases the risk of caries due to prolonged contact between sugars in the consumed food or liquid and cariogenic bacteria on the susceptible teeth [9]. To decrease the risk of developing ECC, the AAPD encourages professional and athome preventive measures that include: avoiding frequent consumption of liquids and/or solid foods containing sugar, in particular sugar-sweetened beverages (e.g., juices, soft drinks, sports drinks, sweetened tea) in a cup. In this case sweet foot and soft drinks should not be taken out of the main meals. They should not be consumed during other activities and before bed- and night-time.

Prophylaxis of the tooth decay in carbohydrate nutrition. We recommended: Low consumption of mono- and disaccharides; Increasing polysaccharides intake; Reducing the frequency and the duration of the intake.

Health Promotion and Education: Regular dental visits each 3 months.

\section{Discussion}

According to Andreeva's results in Bulgaria (2018), the biggest caries involvement is found in children under 5 years of age. This result, R. Andreeva, determines from 
children with early childhood caries whose dmft index is the highest. Values are obtained from untreated carious lesions in the primary dentition. Prematurely extracted teeth at this early age are low [10]. According to other authors, the harmful social and biological risk factors accumulated in early childhood contribute to the development of a high level of ECC. Additionally, newly-erupted teeth, because of immature enamel, and teeth with enamel hypoplasia may be at higher risk of developing caries [11].

The consequences of ECC often include a higher risk of new carious lesions in both the primary and permanent dentitions [12,13], hospitalizations and emergency room visits $[14,15]$, high treatment costs [16], loss of school days [17], diminished ability to learn [18], and diminished oral health-related quality of life [19].

However, new tools for bacterial identification (polymerase chain reaction techniques, 16s rRNA gene sequencing) are revealing the complexity of the oral microbiome and other bacterial species that may be associated with ECC [20]. MS maybe transmitted vertically from caregiver to child through salivary contact, affected by the frequency and amount of exposure [21]. Infants whose mothers have high levels of MS, a result of untreated caries, are at greater risk of acquiring the organism earlier than children whose mothers have low levels [22]. Horizontal transmission - between other members of a family or children in daycare also occurs [22].

In children with severe caries in early childhood and their complications primary teeth need a restoration, and in heavier cases and extraction. According to Dimitrova D. and co-authors of 2018, crowning prosthesis in the primary frontal sectors of the jaw improves the sound articulation and the pronunciation of the consonant sounds. This is a factor for the normal social and psychological development of children. From another perspective, authors report that placed on non-removable crown structures provide the opportunity to realize the full use of the essential macronutrients vital to the processes of growth and development in childhood $[23,24]$. In conclusion, many authors writing on the topic are united that further research could help to set aims for biological interventions in the development of the caries process and thus contribute to improving prevention.

While the treatment of this serious problem is also associated with some of orthodontics deformations $[25,26]$ and public dental health $[2,27,28]$. ECC is a complex of aesthetic and functional problem. The incidence and severity of the loss of height of the interdental papillae increases with age [29]. The latest findings say that the strongest risk factors associated with early childhood caries was the presence of enamel defects, presence of dentinal caries and high levels of mutans streptococci [30].

\section{CONCLUSION}

1. Children who have suffered from ECC should be treated by minimally invasive cavity preparation with preventive fillings for primary teeth. 2. The restorations for teeth are made of modern adhesives such as glass-ionomer cements and compomers. 3. If resin-modified glass ionomer cement are applied, it is necessary to observe the filling made to the physiological eruption of the permanent tooth and the extraction of the primary tooth. 4. Secondary prophylaxis and implementing oral hygiene measures no later than the time of eruption of the first primary tooth.

\section{REFERENCES}

[1] Hallett KB, PK. Pattern and severity of early childhood caries. Community Dentistry and oral epidemiology. 2006;34(1):25-35.

[2] Drury Th. F, Horowitz Am, Ismail AI, Maertens MP, Rozier RG, Selwitz RH. Diagnosing and Reporting Early Childhood Caries for Research Purposes: A Report of a Workshop Sponsored by the National Institute of Dental and Craniofacial Research, the Health Resources and Services Administration, and the Health Care Financing Administration. Journal of Public Health Dentistry. 1999; 59(3): 192-197.

[3] Andreeva R. Demografic characteristics of treated under general anesthesia. Scripta Scientifica Salutis Publicae. 2018; 4:59-65.

[4] Andreeva R. Dental status assessment of children treated under general anesthesia. Scripta Scientifica Medicinae Dentalis. 2018;4(1):12-17.

[5] Hallett KB, PK. Social and behavioural determinants of early childhood caries. Australian Dental Journal. 2003; 48(1):27-33.

[6] Drury TF, Horowitz AM, Ismail AI, et al. Diagnosing and reporting early childhood caries for research purposes.J Public Health Dent 1999; 59(3): 192-7. 
[7] Gisela Ladda Tayanin.Oral Health Database. https://www.mah.se/CAPP/Methods-andIndices /Oral-Hygiene-Indices/Silness-LoeIndex/

[8] Kanasi E, Johansson J, Lu SC, et al. Microbial risk markers for childhood caries in pediatrician's offices. J Dent Res 2010; 89(4): 378-83.

[9] Tinanoff NT, Palmer C. Dietary determinants of dental caries in preschool children and dietary recommendations for preschool children. J Pub Health Dent 2000; 60(3): 197-206.

[10] Andreeva R. Assessment of the indications for dental treatment of children under general anesthesia. Scripta Scientifica Medicinae Dentalis. 2018; 4(1): 18-22.

[11] Caufield PW, Li Y, Bromage TG. Hypoplasiaassociated severe early childhood caries: A proposed definition. J Dent Res. 2012; 91(6): 544-50.

[12] O'Sullivan DM, Tinanoff N. The association of early childhood caries patterns with caries incidence in preschool children. J Public Health Dent. 1996; 56(2): 81-3.

[13] Al-Shalan TA, Erickson PR, Hardie NA. Primary incisor decay before age 4 as a risk factor for future dental caries. Pediatr Dent. 1997;19(1):37-41.

[14] Ladrillo TE, Hobdell MH, Caviness C. Increasing prevalence of emergency department visits for pediatric dental care 1997-2001. J Am Dent Assoc. 2006; 137(3):379-85.

[15] Griffin SO, Gooch BF, Beltran E, Sutherland JN, Barsley R. Dental services, costs, and factors associated with hospitalization for Medicaideligible children, Louisiana 1996-97. J Public Health Dent. 2000; 60(3):21-7.

[16] Agency for Healthcare Research and Quality. Total dental care expenditure, 2010, Medical Expenditure Panel Survey. Available at: "http: / / meps.ahrq.gov/mepsweb/data_files / publications /st415/stat415.pdf." Accessed April 9, 2015. (Archived by WebCite® at: "http://www. webcitation.org/6XezI3w7Y")

[17] Edelstein BL, Reisine S. Fifty-one million: A mythical number that matters. J Am Dent Assoc. 2015; 146(8):565-6.
[18] Blumenshine SL, Vann WF, Gizlice Z, Lee JY. Children's school performance: Impact of general and oral health. J Public Health Dent. 2008; 68(2): 82-7.

[19] Filstrup SL, Briskie D, daFonseca M, Lawrence L, Wandera A, Inglehart MR. The effects on early childhood caries (ECC) and restorative treatment on children's oral health-related quality of life (OHRQOL). Pediatr Dent. 2003; 25(5): 431-40.

[20] Li Y, Tanner A. Effect of antimicrobial interactions on the oral microbiota associated with early childhood caries. Pediatr Dent. 2015; 37(3): 226-44.

[21] Li Y, Caufield PW. The fidelity of initial acquisition of mutans streptococci by infants from their mothers. J Dent Res. 1995;74(2):681-5.

[22] BerkowitzRJ.Mutansstreptococci:Acquisitionand transmission. Pediatr Dent. 2006;28(2):106-9.

[23] Dimitrova D, Andreeva R, Dimova-Gabrovska M. Application of Aesthetic Crowns in Children Patients. Varna Medical Forum. 2018;7:173-177.

[24] Konstantinova D, Dimova M, Naydenova D. Impact of food preferences on the development of pathological changes in the masticatory apparatus in young patients. Journal of IMAB. 2016; 22(3): 1230-1234.

[25] Valcheva Z, Arnautska H, Dimova M, Ivanova $\mathrm{G}$, Atanasova I. The role of mouth breathing on dentition development and formation. Journal of IMAB. 2017;23(4):1878-1882.

[26] Dimova-Gabrovska M, Arnautska H, Konstantinova D, Tsvetkov N, Gerdzhikov I, Georgiev T, Andreeva R. Correlation between deep bite and periodontal changes in CMDpatients. PRAEMEDICUS Since 1925, Medical University Sofia. 2016; 33(1): 25-28.

[27] Pechere JC et al. Non-compliance with antibiotic therapy for community infections: a global survey. International Journal of Antimicrobial Agents. 2007; 29:245-253.

[28] World Health Organization. How to stop antibiotic resistance? Here's a WHO prescription. 2015. http://www.who.int/mediacentre/commen taries/stop-antibiotic-resistance/en/. 
[29] Georgieva Ir, Peev St, Gerova T, Miteva M, Bazitova-Zlateva M. Interdental papillae height assessment in the aesthetic zone of the maxilla. Scripta Scientifica Medicinae Dentalis, Medical University of Varna. 2017; 3(2): 7-12.
[30] Kirthiga M, Murugan M, Saikia A, Kirubakaran R. Risk Factors for Early Childhood Caries: A Systematic Review and Meta-Analysis of Case Control and Cohort Studies. Pediatr Dent. 2019; 41(2): 95-106.E18-E23.

Citation: Dobrinka M. Damyanova. Severe Early Childhood Caries - A Clinical Case Report. Archives of Dentistry and Oral Health. 2019; 2(1): 11-17.

Copyright: (C) 2019 Dobrinka M. Damyanova. This is an open access article distributed under the Creative Commons Attribution License, which permits unrestricted use, distribution, and reproduction in any medium, provided the original work is properly cited. 